\title{
Genotypic differences in leaf gas exchange and growth responses to deficit irrigation in reticulatus and inodorus melons (Cucumis melo L.)
}

\author{
S.P. SHARMA ${ }^{* * * *,+}$, D.I. LESKOVAR ${ }^{*}$, and K.M. CROSBY ${ }^{* *}$ \\ Texas A\&M AgriLife Research and Extension Center, Texas A\&M University, Uvalde, TX, USA* \\ Department of Horticultural Sciences, Texas A\&M University, College Station, TX, USA** \\ Department of Vegetable Science, Punjab Agricultural University, Ludhiana, India ${ }^{* * *}$
}

\begin{abstract}
Leaf gas exchange and growth responses of three melon cultivars, i.e., Mission, Da Vinci (var. reticulatus), and Super Nectar (var. inodorus) to two irrigation regimes, 50 and 100\% crop evapotranspiration (ETc) were investigated under water-limited conditions of southwest Texas. In 2012, deficit irrigation (50\% ETc) significantly decreased above-ground biomass, leaf area, leaf number, and specific leaf area, while leaf gas exchange, relative water content, water potential, chlorophyll fluorescence $\left(\mathrm{F}_{\mathrm{v}} / \mathrm{F}_{\mathrm{m}}\right)$, and chlorophyll content (SPAD index) were not affected. However, in the drier year 2011, deficit irrigation significantly reduced net photosynthetic rate $\left(P_{\mathrm{N}}\right)$ and stomatal conductance $\left(g_{\mathrm{s}}\right)$. Further, the responses to water deficit varied with cultivars. At $50 \% \mathrm{ETc}, P_{\mathrm{N}}$ and $g_{\mathrm{s}}$ were maintained in cv. Da Vinci while decreased in Mission and Super Nectar. Thus, the late maturing cv. Super Nectar appeared to be more sensitive to drought stress, possibly due to the decrease in leaf area and $P_{\mathrm{N}}$.
\end{abstract}

Additional key words: chlorophyll fluorescence; muskmelon; photosynthesis; specific leaf area; stomatal conductance; transpiration.

\section{Introduction}

The increased frequency and intensity of drought events and severe restrictions on groundwater use for irrigated crops are likely to affect melon cultivation in semiarid regions of Texas (Leskovar et al. 2001, Leskovar and Piccinni 2005) and worldwide. Thus, to sustain melon production in the region, the implementation of the "more crop per drop' irrigation strategy is urgently needed (Blum 2011). Under sustained deficit irrigation plants are supplied with water below their ETc demands throughout the growing season (Fereres and Soriano 2007) and thus, are deliberately exposed to a gradual moisture stress which, depending upon the crop and/or cultivar sensitivity, may have deleterious effects on crop physiology, growth, and yield.

Plants can avoid losses associated with drought stress through morphological and physiological adaptations (Blum 2005), but these responses may vary with crops/ cultivars, growth stages, environments and timing, severity and duration of water stress (Cattivelli et al. 2008). Some examples include improved root growth in melons (Sharma et al. 2014, 2018), decrease in leaf dry mass ratio in wheat (Triticum aestivum L) (Boogaard et al. 1996), reduction in specific leaf area in Amaranthus spp. and in Arundo donax L (Liu and Stützel 2004, Romero-Munar et al. 2018), decrease in chlorophyll (Chl) content (Mafakheri et al. 2010), and restricted shoot growth with unchanged root growth in maize (Zea mays L.) (Sharp and Davies 1979). Most of these growth traits are rapidly affected by very mild stress, while, prolonged water deficit can adversely affect leaf gas-exchange characteristics (Huck et al. 1983) due to stomatal closure and related low $C_{\mathrm{i}}$ (Raschke and Hedrich 1985) and certain other nonstomatal factors (Janoudi et al. 1993). Under greenhouse conditions, water stress decreased net $\mathrm{CO}_{2}$ assimilation rate $\left(P_{\mathrm{N}}\right), g_{\mathrm{s}}$, $C_{\mathrm{i}}$, and transpiration rate $(E)$ of melon seedlings (Huang et al. 2010, Agehara and Leskovar 2012). Most of these studies have been conducted under controlled conditions, while field experiments designed to assess the impact of water deficit on growth and leaf gas exchange of melons are lacking.

Plant morphological and physiological processes differ in their sensitivity to water stress. Subbarao et al. (1995) reported that leaf area expansion is more sensitive to

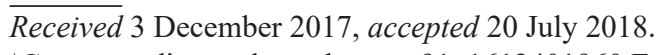

${ }^{+}$Corresponding author; phone: +91-1612401960 Ext. 370, email: sharmasp@pau.edu

Abbreviations: $\mathrm{ABM}$ - aboveground biomass; $C_{\mathrm{a}}-$ ambient $\mathrm{CO}_{2}$ concentration; Chl - chlorophyll; $C_{\mathrm{i}}-$ intercellular $\mathrm{CO}_{2}$ concentration; $E$ - transpiration rate; $\mathrm{ETc}$ - crop evapotranspiration; $\mathrm{F}_{\mathrm{v}} / \mathrm{F}_{\mathrm{m}}-$ maximal quantum yield of PSII photochemistry; $g_{\mathrm{s}}-$ stomatal conductance; $\mathrm{K}_{\mathrm{c}}-$ crop coefficients; $\mathrm{L}_{\mathrm{s}}-$ stomatal limitations; $\mathrm{LA}$ - leaf area per plant; $\mathrm{LN}$ - number of leaves per plant; $P_{\mathrm{N}}-$ net photosynthetic rate; RWC - relative water content; SLA - specific leaf area; SPAD - chlorophyll index; TFY - total fruit yield; WUE - water-use efficiency $\left(P_{\mathrm{N}} / E\right)$.

Acknowledgements: This project was supported by Texas Department of Agriculture (TDA No. 504610-80980), "Production and Marketing Strategies for Melons and Artichokes". Cultivars seeds were supplied by Seminis and Sakata Seeds. We acknowledge the support of Carrie Hensarling, Manuel Figueroa-Pagán, Juan Esquivel, and Ezequiel Cardona for their technical assistance in the field and laboratory. 
water stress than photosynthesis and transpiration in grain legumes. Further, Karimi et al. (2015) emphasized that ability to preserve relative water content was involved in drought-tolerance mechanism in almond. While Ashraf et al. (2002) argued that the decreased $P_{\mathrm{N}}$ is the most common physiological response to moisture stress, due to stomata closure and inhibition of Calvin cycle enzymes like Rubisco, particularly when plants are exposed to gradual water stress under field conditions (Medrano et al. 1997). Indeed, it is the total crop photosynthesis, not the $P_{\mathrm{N}}$, that contributed in the past to improvement in yield of grain crops, thus the maintenance of leaf area is more important than $P_{\mathrm{N}}$ (Richards 2000). Within this context, identifying traits useful for selecting melon cultivars tolerant to soil moisture deficit has become a priority in this study.

Melons are highly productive under well-watered conditions (Sharma et al. 2014) and are considered to be sensitive to water stress. Under water-deficit conditions, melon crop exhibited significant reductions in fruit yield (Fabeiro et al. 2002, Cabello et al. 2009) and quality (Lester et al. 1994, Long et al. 2006). The high stomatal density on both upper and lower surface of melon leaves (Abdulraham et al. 2011), may result in high stomatal conductance and hence enhanced sensitivity to mesophyll or parenchymatous outer cortical tissue dehydration. Genetic adaptive responses to water deficit have been reported in several crops, such as Amaranthus spp. (Liu and Stützel 2004), chickpea (Cicer arietinum L.) (Mafakheri et al. 2010), cotton (Gossypium hirsutum L. r. latifolium Hutch) (de Brito et al. 2011), okra (Abelmoschus esculentus (L.) Moench) (Razavi et al. 2008) and Prunus dulcis Mill. (Karimi et al. 2015), and tomato (Fullana-Pericàs et al. 2017). Melon has shown a positive association between $P_{\mathrm{N}}$ and fruit yield (Kitroongruang et al. 1992) possessing a wide genetic variability for leaf gasexchange traits (De et al. 2008). However, morphological and physiological adaptation responses to water deficit of melon cultivars from diverse horticultural groups have not been investigated.

The objective of this study was to determine the effect of deficit irrigation (50\% ETc) on growth adaptation and physiological traits of three diverse melon cultivars belonging to the muskmelon, Tuscan, and honeydew group. The selected cultivars differ in their fruit shape, size, color, ripening behavior, and maturity. It was hypothesized that differences in fruit characteristics between these cultivars would also be exhibited in morphological and photosynthetic adaptation responses to deficit soil moisture. We expect, this information will be useful in melon breeding for screening cultivars with specific traits linked to drought adaptation.

\section{Materials and methods}

Plant material and treatments: Three melon cultivars, i.e., Mission (var. reticulatus; muskmelon type), Da Vinci (var. reticulatus; Tuscan type), and Super Nectar (var. inodorus; honeydew type) were grown under field conditions at the Texas A\&M AgrilLife Research and Extension Center at Uvalde, TX $\left(29^{\circ} 13^{\prime} \mathrm{N}, 99^{\circ} 45^{\prime \prime} \mathrm{W}\right)$, on a clay soil (Hyperthermic Aridic Calciustolls) during 2011 and 2012 seasons. These cultivars were chosen because they are the representative and highly productive varieties representing important commercial horticultural melon groups. Further, no previous study has investigated their growth and photosynthetic responses to water deficit under field conditions.

The experimental site has a semiarid climate with average annual high/low temperatures of $27.4 / 13.6^{\circ} \mathrm{C}$ and a mean annual precipitation of $663 \mathrm{~mm}$. The mean annual evapotranspiration (ET) is $1522 \mathrm{~mm}$, which is more than twice the mean annual rainfall. Average minimum and maximum temperatures are given in Fig. 1S (supplement) while, Fig. 1 depicts the vapor pressure deficit and rainfall events of the experimental site.

Irrigation rates $(50 \% \mathrm{ETc}$ and $100 \% \mathrm{ETc})$ and cultivars

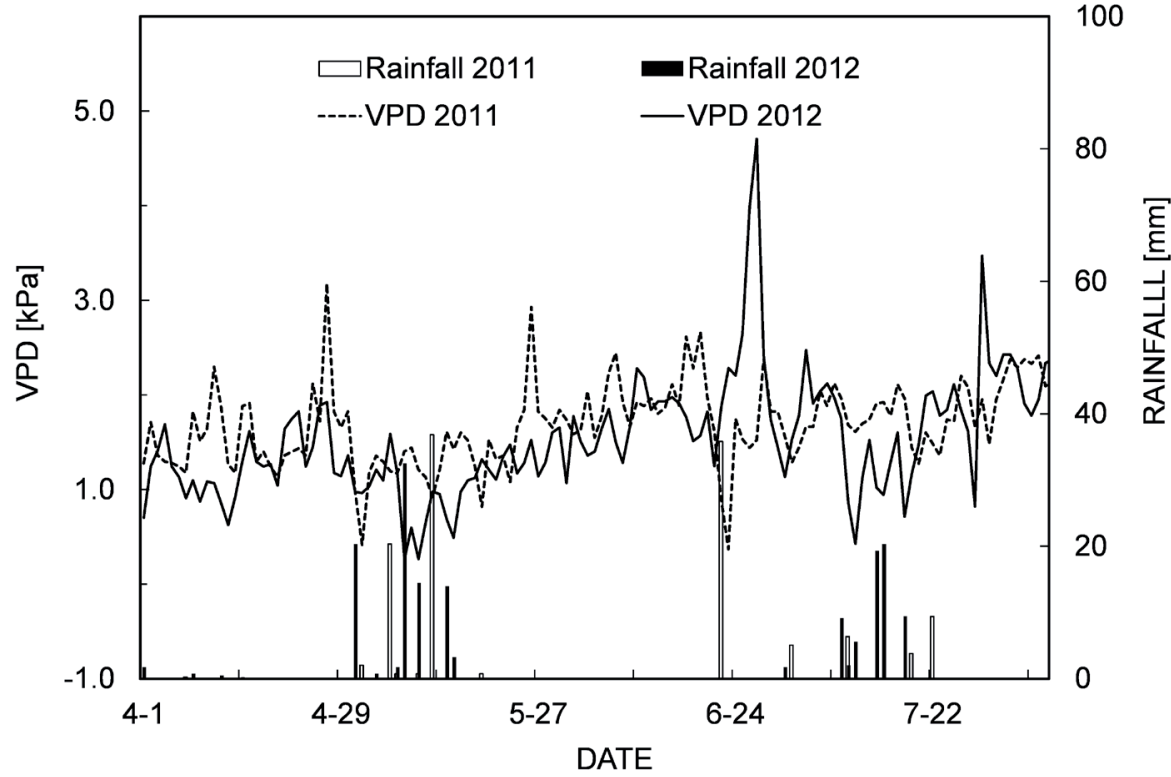

Fig. 1. Daily vapor pressure deficit (VPD) (lines) and rainfall (RF) events (bars) at Uvalde, TX in 2011 and 2012 seasons. 
were arranged in a split plot design, with three replicates. Seeds were planted on raised beds $(2.03 \mathrm{~m}$ row to row, $0.30 \mathrm{~m}$ plant to plant spacing) covered with black plastic mulch thickness of $0.02 \mathrm{~mm}$ on 1 April 2011 and 15 April 2012. The irrigation was applied as subsurface drip based on the daily crop evapotranspiration (ETc) which was calculated as a product of the reference evapotranspiration $\left(\mathrm{ET}_{0}\right)$ obtained from the lysimeter facility located at the Texas A\&M Center (Ko et al. 2009) and the stage specific $\mathrm{K}_{\mathrm{c}}$. $\mathrm{K}_{\mathrm{c}}$ values were used as; $\mathrm{K}_{\mathrm{c} \text { ini }}=0.5, \mathrm{~K}_{\mathrm{c} \text { mid }}=0.85$, and $\mathrm{K}_{\mathrm{c} \text { end }}=0.60$ (Allen et al. 1998). The irrigation requirement was calculated with adjustments for effective rainfall $(50 \%)$, black plastic mulch (bare soil $\left.\mathrm{K}_{\mathrm{c}}=0.2\right)$ (Shinohara et al. 2011, Sharma et al. 2017), effective irrigation wetting bed width (estimated at $70 \%$ ) and canopy growth. Irrigation was triggered twice a week when cumulative irrigation requirement reached at $10 \mathrm{~mm}$ approximately. The drip tape (T-Tape, John Deere, Moline, IL, USA) with $1.02 \mathrm{~L} \mathrm{~h}^{-1}$ flow rate at $55 \mathrm{kPa}$ was buried in the middle of each bed at a 15-cm depth with drippers spaced at 30.48 $\mathrm{cm}$. Irrigation amount applied was calculated from drip tape flow rate, duration of irrigation applied (hours) and the linear length irrigated. Total fertilizers $90 \mathrm{~N}-42 \mathrm{P}-30 \mathrm{~K}$ $\mathrm{kg} \mathrm{ha} \mathrm{h}^{-1}$ and $73 \mathrm{~N}-30 \mathrm{P}-36 \mathrm{~K} \mathrm{~kg} \mathrm{ha} \mathrm{K}^{-1}$ were applied through fertigation during 2011 and 2012 seasons, respectively.

During the first $34 \mathrm{~d}$ after transplantation (DAP) in 2011 and 38 DAP in 2012, both irrigation rate treatments received full irrigation (i.e., equivalent $100 \% \mathrm{ETc}, 78 \mathrm{~mm}$ and $27 \mathrm{~mm}$, respectively) water to ensure good germination and seedling establishment. Since the objective of the study was to expose the cultivars to a mild gradual stress, the differential irrigation of melon cultivars began on 5 May 2011 and 23 May 2012, with 50\% and $100 \%$ ETc treatments receiving 184 and $335 \mathrm{~mm}$ water for 27 irrigation events in 2011, respectively. In 2012, 32 applications after May 23 applied 200 and $382 \mathrm{~mm}$ for $50 \%$ and $100 \%$ ETc, respectively. Therefore, the deficit irrigation (50\% ETc) actually received 63\% (261 vs. $413 \mathrm{~mm}$ ) and 55\% (227 vs. $409 \mathrm{~mm}$ ) of irrigation water applied in 2011 and 2012, respectively.

Gas exchange and $\mathrm{Chl}$ fluorescence: Net photosynthetic rate $\left(P_{\mathrm{N}}\right)$, stomatal conductance $\left(g_{\mathrm{s}}\right)$, intercellular $\mathrm{CO}_{2}$ concentration $\left(C_{\mathrm{i}}\right)$, and transpiration rate $(E)$ were measured at 53, 67, 95, and 110 DAP in 2011 and 36, 50, 64, 81, and 95 DAP in 2012. Two random plants were selected in each plot and fully expanded mature leaves $\left(4^{\text {th }}\right.$ or $5^{\text {th }}$ from the main growing vine tip) were used for measurements. A portable photosynthesis system LI-6400XT (LI-COR Inc., Lincoln, NE, USA) equipped with an open-flow infrared gas analyzer was used at a steady state (PAR of 2,000 $\mu \mathrm{mol}$ $\mathrm{m}^{-2} \mathrm{~s}^{-1}$, reference $\mathrm{CO}_{2}$ concentration of $400 \mu \mathrm{mol} \mathrm{mol}{ }^{-1}$, air flow rate of $500 \mu \mathrm{mol} \mathrm{s}^{-1}$, and block temperature of $30^{\circ} \mathrm{C}$ ) for all measurements (Agehara and Leskovar 2012). The stomatal limitations $\left(\mathrm{L}_{\mathrm{s}}\right)$ to photosynthesis were computed by using the formula, $\mathrm{L}_{\mathrm{s}}=1-C_{\mathrm{i}} / C_{\mathrm{a}}$ (Jones 1985).

To measure the efficiency of light absorption, Chl fluorescence was determined using a portable pulse modulated Chl fluorometer OS-30P (OPTISCIENCES, USA) with 1 -s excitation pulse $(660 \mathrm{~nm})$ and saturation intensity of 3,500 $\mu$ mol(photon) $\mathrm{m}^{-2} \mathrm{~s}^{-1}$ after 30 -min dark adaptation of the same leaves used for gas-exchange measurements by fixing dark-adaptation clips on each leaf. The sensor of the fluorometer was inserted in the cuvette on the leaf clip and $F_{v} / F_{m}$ values were recorded. Since, $\mathrm{F}_{\mathrm{v}} / \mathrm{F}_{\mathrm{m}}$ gives the measure of efficiency of excitation energy captured by the open PSII reaction centers (Oyetunji et al. 2007), it provides an indication of the photo-/thermostability of the photosynthetic machinery. Chl fluorescence was recorded at 36, 64, and 81 DAP in 2012 season. Leaf Chl index was also measured immediately on the same leaves using a Chl SPAD-502 meter (Konica Minolta Sensing, Tokyo, Japan). Five readings were taken per leaf on two plants per plot, around $1 \mathrm{~cm}$ away from the margin avoiding major leaf veins. All measurements were done between 11:00 to 15:00 h (Hamidou et al. 2007).

Plant water status: Midday leaf water potential $\left(\Psi_{1}\right)$ was measured between 12:00 and 14:00 $\mathrm{h}$ as described in Agehara and Leskovar (2012), using a pressure chamber (Model 3005; Soil moisture Equipment, Santa Barbara, $\mathrm{CA}$ ). For measuring relative water content (RWC), one entire leaf from two plants per plot was collected. After fresh mass (FM) was recorded, leaves were floated on deionized water in a petri dish and hydrated in darkness for $4 \mathrm{~h}$. Thereafter, the turgid mass (TM) was recorded, and samples were subsequently dried to a constant mass at $85^{\circ} \mathrm{C}$ to determine the dry mass (DM) (Goreta et al. 2007). Relative water content expressed as a percentage was calculated as follows:

$\mathrm{RWC}=[(\mathrm{FM}-\mathrm{DM}) /(\mathrm{TM}-\mathrm{DM})] \times 100$

Growth and yield: Total leaf area and dry matter content of leaves, stems, and fruit were determined twice, at 37 (i.e., before starting differential irrigation) and 68 DAP (i.e., $30 \mathrm{~d}$ after applying deficit irrigation). Six plants per treatment were sampled by cutting them at ground level and separated into leaf, stem, and fruits. At each sampling total leaf area per plant (LA) was measured using a portable leaf area meter (LI 3100, Licor, Lincoln, Nebraska, USA). Leaf, stem, and fruit fresh mass was recorded and all three plant components were dried to a constant mass at $85^{\circ} \mathrm{C}$ to determine their respective dry masses to calculate the above ground biomass (ABM). Specific leaf area (SLA) was calculated as the total plant leaf area divided by leaf dry mass.

Fruits were harvested at half to full slip stage between 18 June (78 DAP) to 5 August 2011 (126 DAP), and between 25 June (71 DAP) and 24 July 2012 (100 DAP), and total fruit yield (TFY) $\left[\mathrm{t} \mathrm{ha}^{-1}\right]$ was recorded.

Statistical analysis: Data for each variable were subjected to the analysis of variance (ANOVA) with a split plot design using generalized linear model procedures ( $S A S$ 9.1, SAS Inst., Cary, N.C., USA). Irrigation regime (50\% and $100 \%$ ETc) was the main plot, cultivar (Mission, Da Vinci, and Super Nectar) the subplot, and sampling dates (DAP) the sub-sub plot factor (McIntosh 1983). Where significant main effects were found, means were separated by Duncan's multiple-range test. Relationships among $P_{\mathrm{N}}$, 
$g_{\mathrm{s}}, E, \mathrm{~F}_{\mathrm{v}} / \mathrm{F}_{\mathrm{m}}, \mathrm{SPAD}, \mathrm{LA}, \mathrm{SLA}$, leaf number (LN), TFY, WUE, and ABM were determined by correlation analysis.

\section{Results}

Overall, deficit irrigation $(50 \% \mathrm{ETc})$ resulted in significant decrease in $P_{\mathrm{N}}$ and $g_{\mathrm{s}}$ in the 2011 season (Table 1). Data for 2012 showed no statistically significant trend (Table 2). The melon cultivars also exhibited significant differences for $P_{\mathrm{N}}$ and $E$ parameters in both seasons, with Da Vinci having the lowest values for both traits as compared to cv. Mission and Super Nectar. The lowest $g_{s}$ was also recorded in Da Vinci in both years, but the difference was only significant in 2012 (Tables 1, 2). Sampling dates also had significant effect on all the leaf gas-exchange parameters in 2011 and 2012 seasons (Tables 1, 2), indicating that leaf gas exchange varied with the phenological stages and weather conditions. In 2011, leaf gas-exchange parameters, i.e., $g_{\mathrm{s}}, E$, and $C_{\mathrm{i}}$ followed a gradual decrease over the sampling dates; however, both $P_{\mathrm{N}}$ and water-use efficiency (WUE; $P_{\mathrm{N}} / E$ ) increased at 67 DAP though $P_{\mathrm{N}}$ decreased thereafter, while WUE remained unchanged at 95 DAP, and then increased at 110 DAP. Similarly, in 2012, $P_{\mathrm{N}}$ and WUE significantly increased up to 64 DAP and decreased thereafter. While, $g_{\text {s }}$ increased at 50 DAP and decreased during rest of the season. Further, $E$ and $C_{\mathrm{i}}$ followed the decreasing trend, except a significant increase at 95 DAP. Stomatal limitations $\left(\mathrm{L}_{\mathrm{s}}\right)$ significantly increased between 64 and 81 DAP and again declined at 95 DAP.

In 2011, cultivar $\times$ sampling date interactions were significant for $P_{\mathrm{N}}, g_{\mathrm{s}}, E$, and $C_{\mathrm{i}}$ (Table 1), indicating that leaf gas-exchange responses to deficit irrigation varied among the cultivars and sampling dates (Fig. 2). $P_{\mathrm{N}}$ increased up to 67 DAP in Mission, 95 DAP in cv. Da Vinci, while started to decrease in cv. Super Nectar after 53 DAP (Fig. 2). Similar trends were observed for $g_{\mathrm{s}}$ and $E$. $C_{\mathrm{i}}$ decreased in all the cultivars at $67 \mathrm{DAP}$, it remained unchanged in cv. Mission and Da Vinci up to 95 DAP, but decreased in cv. Super Nectar at 95 DAP. Thus, the decrease in gas exchange was more rapid in Mission, while the decrease was consistent in Da Vinci, and it was more variable in Super Nectar. WUE showed an increasing trend over time for all cultivars. Fig. 3 shows the irrigation rate and cultivar interactions for $P_{\mathrm{N}}$ and $g_{\mathrm{s}}$ between 53 and 110 DAP in 2011. Deficit irrigation did not reduce $P_{\mathrm{N}}$ and $g_{\mathrm{s}}$ in cv. Da Vinci, rather it was improved at 67 DAP.

Similarly, in 2012, cultivar $\times$ sampling date interactions were significant for $P_{\mathrm{N}} g_{\mathrm{s}}, E, C_{\mathrm{i}}$, and $\mathrm{L}_{\mathrm{s}}$ (Table 2). In general, $P_{\mathrm{N}}$ and $\mathrm{L}_{\mathrm{s}}$ increased up to $64 \mathrm{DAP}$, however, $g_{\mathrm{s}}$ decreased significantly at 64 DAP and remained lesser thereafter. WUE showed a similar trend in all the cultivars and increased up to 64 DAP and decreased thereafter (Fig. 4).

Deficit irrigation did not affect water potential $\left(\Psi_{1}\right)$ and relative water content (RWC) of melon cultivars when measured at 81 DAP (data not shown). However, under $50 \%$ ETc, a numerical increase in $\Psi_{1}$ was recorded for cv. Mission and Super Nectar. RWC of all the three cultivars remained similar at both irrigation rates.

Chl fluorescence $\left(\mathrm{F}_{\mathrm{v}} / \mathrm{F}_{\mathrm{m}}\right)$ in melons was not affected by deficit irrigation (data not shown). Similarly, 50\% ETc did not cause any leaf chlorosis in all the cultivars as indicated by no significant differences in Chl index (data not shown). Deficit irrigation caused a significant increase in stomatal density of in cv. Mission as compared to $100 \%$ ETc (Fig. 2S, supplement). The increase in stomatal density was similar in Da Vinci and Super Nectar, but not significant.

No differences in LA, ABM and SLA were observed between the irrigations rates at $37 \mathrm{DAP}$ (i.e., before starting the differential irrigation). However, at 68 DAP (i.e., $30 \mathrm{~d}$ of differential irrigation), 50\% ETc significantly reduced leaf number per plant (LN) by $43 \%$, leaf area per plant (LA) by $50 \%$, aboveground biomass per plant (ABM) by $37 \%$, and specific leaf area (SLA) by $14 \%$ as compared to $100 \%$ ETc (Table 3 ). These reductions varied in extent with cultivars. Leaf area and specific area decreased in all the cultivars while, LN and ABM decreased in Mission and Da Vinci. The trend was similar in Super Nectar, but not significant.

Deficit irrigation caused a significant reduction in leaf (LDM), stem (SDM), and fruit (FDM) dry masses in cv. Mission and Da Vinci as compared to $100 \%$ ETc (Fig. 3S, supplement). In cv. Super Nectar, the reduction was statistically significant only for stem dry mass. Overall, deficit irrigation reduced LDM by 49, 53, and 18\%, SDM by 54,53 , and $21 \%$ and FDM by 40,43 , and $3 \%$ in cv. Mission, Da Vinci, and Super Nectar, respectively.

Under 50\% ETc, the ABM had a strong correlation with leaf area (LA) $(r=0.920)$ and number of leaves per plant (LN) $(r=0.888)$ (Table $1 \mathrm{~S}$, supplement). Similarly, TFY had a significant correlation with LA $(r=0.736)$, LN $(r=0.873)$ and SLA $(r=0.786)$ which indicates that under water deficit a decrease in TFY and ABM was associated with decrease in leaf area per plant. Moreover, under $100 \%$ ETc, ABM was positively correlated with LA. TFY had no correlation with ABM, LA and LN. This indicates that under optimum moisture conditions an increase in LA can result in enhanced ABM but not necessarily a corresponding increase in fruit yield.

There were significant interactions between irrigation rates and cultivars for total fruit yield in both seasons (Fig. 4S, supplement). Deficit irrigation significantly reduced total fruit yield in all the cultivars in 2012, and a similar trend was observed in 2011 though the reduction in yield was significant only in cv. Super Nectar. The highest yield reduction was measured in cv. Super Nectar, 38\% in 2011 and 33\% in 2012 in response to deficit irrigation. Similarly, cv. Mission and Da Vinci recorded a 26\% and $31 \%$ reduction in TFY in 2012, and $11 \%$ and $14 \%$ in 2011 , respectively.

\section{Discussion}

Melons are usually cultivated in arid to semiarid conditions during hot and dry summers and thus, are often subjected to extreme droughts and high temperatures. These weather extremes adversely affect growth and photosynthetic capacity of plants which in turn reduces their yield potentials (Kusvuran 2010, Sharma et al. 2014). Thus, adjustments in morphological, physiological, and biochemical traits in response to changes in the environment of a crop 


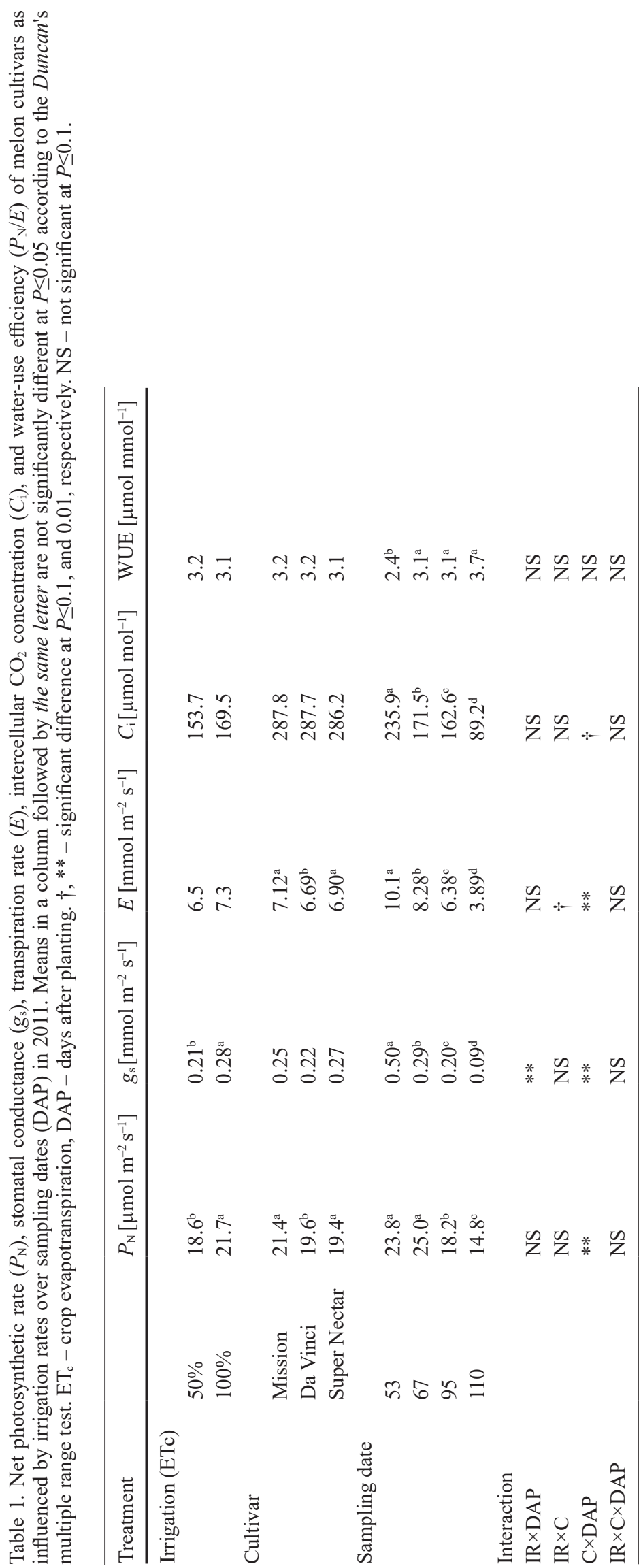




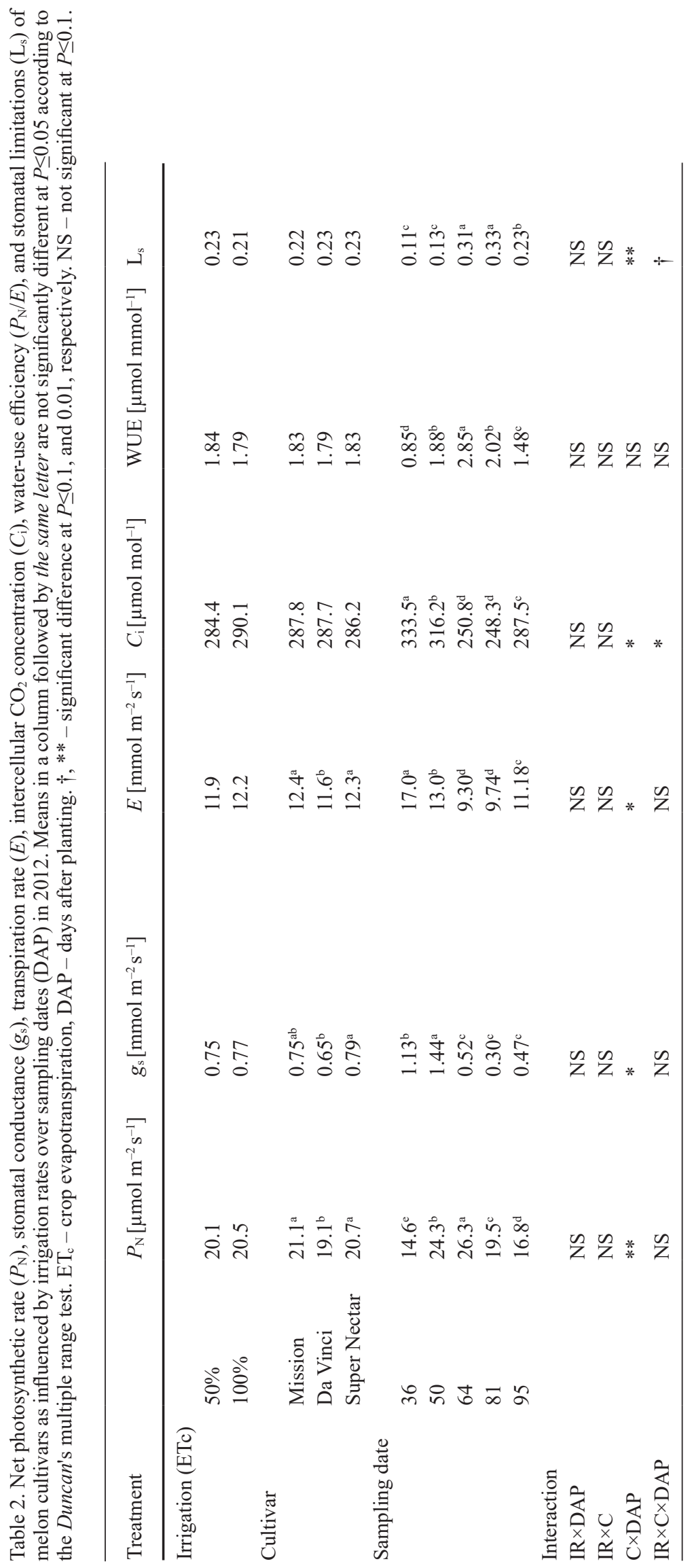




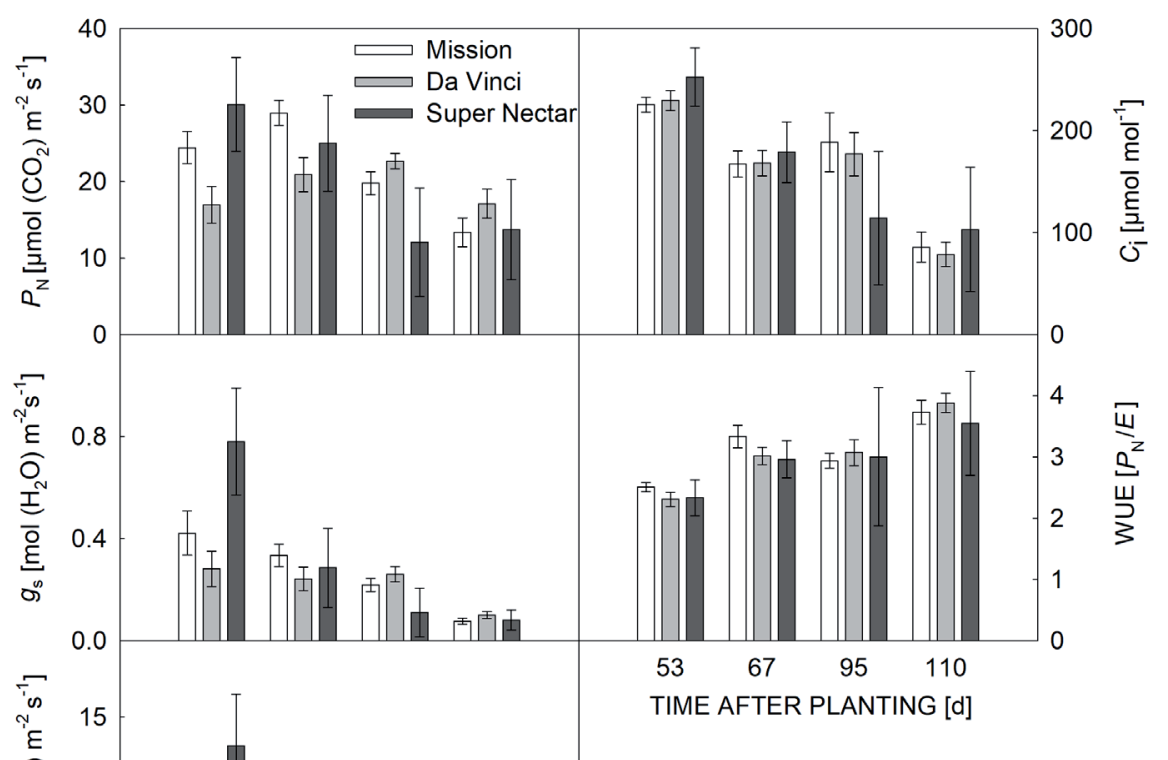

Fig. 2. Net photosynthetic rate $\left(P_{\mathrm{N}}\right)$, stomatal conductance $\left(g_{\mathrm{s}}\right)$, transpiration rate $(E)$; intercellular $\mathrm{CO}_{2}$ concentration $\left(C_{\mathrm{i}}\right)$, and water-use efficiency (WUE, $P_{\mathrm{N}} / E$ ) of melon cultivars between 53 and 110 days after planting in 2011.Vertical bars represent $95 \%$ confidence intervals.

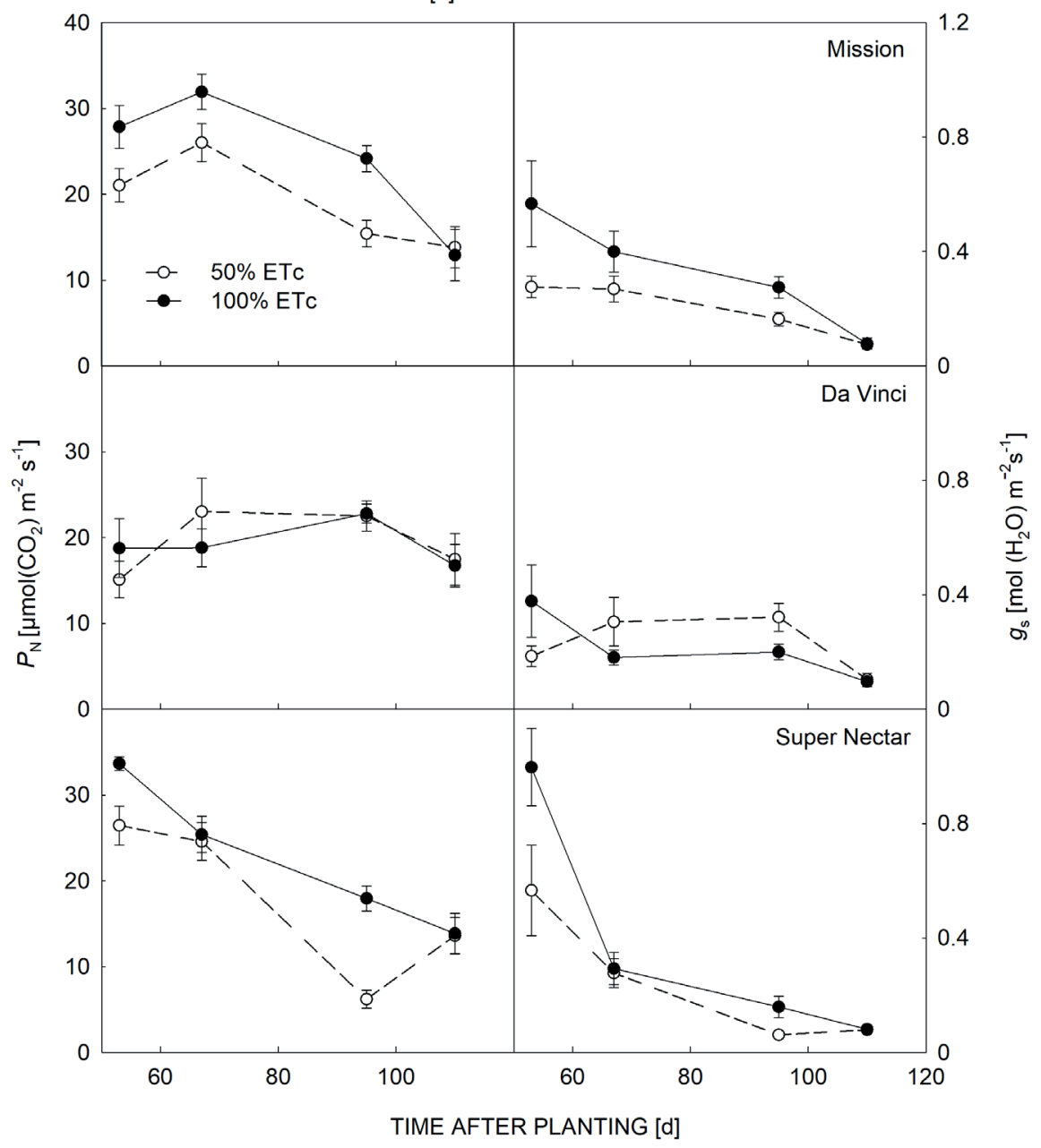

Fig. 3. Net photosynthetic rate $\left(P_{\mathrm{N}}\right)$ and stomatal conductance $\left(g_{\mathrm{s}}\right)$ of melon cultivars in response to irrigation rates over days after planting in 2011. Values are represented as mean $\pm \mathrm{SE}$. 
or cultivar determine its adaptability to water deficit conditions. Kusvuran (2010) mentioned that the potential for drought tolerance exists in melon genotypes, which was further corroborated by a significant genotypic variability for leaf gas-exchange traits in this crop (De et al. 2008). Thus, further information on growth and leaf gas exchange of melon cultivars will enhance understanding of their adaptation mechanisms to water deficit conditions, which can be then applied to implement water saving strategies (e.g., deficit irrigation) with minimum yield losses.

Deficit irrigation $(50 \%$ ETc) reduced the leaf gasexchange parameters in melon in both seasons, but significant differences were only recorded in 2011 (Table 1) and not in 2012 (Table 2). The year to year variation for photosynthetic traits is not unusual in drought-prone environments where stress events vary in timing, duration, and severity (Cattivelli et al. 2008). During this study period, the experimental site experienced the most severe drought since 1950's, with varied drought events in timing and severity in both years (Fig. 1). Overall 2011 was a drier year with a higher VPD (Fig. 1) as compared to 2012, which resulted in significant reduction in $P_{\mathrm{N}}$ and $g_{\mathrm{s}}$ in 2011. Janoudi et al. (1993) also reported that increased VPD induced stomatal closure in cucumber (Cucumis sativus L.) plants, which limited $\mathrm{CO}_{2}$ availability and ultimately resulted in reduced photosynthesis.

Plants under deficit irrigation had a decrease in $P_{\mathrm{N}}$ and $g_{\mathrm{s}}$ (Table 1), suggesting that under water stress stomatal closure prevented water loss at the expense of $\mathrm{CO}_{2}$ for photosynthesis (Agehara and Leskovar 2012). Even though with deficit irrigation, WUE may increase (Sun et al. 2013) but it can be at the expense of reduced leaf gas exchange. The results of this study did not show significant improvement in WUE. However, WUE had a negative correlation with $g_{\mathrm{s}}$ under $50 \%$ ETc in comparison to $100 \%$ ETc $(-0.390 v s .-0.149)$ to $(-0.621 v s .-0.180)$ (Table $1 \mathrm{~S})$, indicating that decrease in $g_{\mathrm{s}}$ increased WUE under waterdeficit conditions (Figs. 2, 4; Table 1S).

Leaf gas exchange of melons varied with growth stages and climatic conditions. $P_{\mathrm{N}}$ increased significantly up to the fruit development stage (67 DAP in 2011 and 64 DAP in 2012). Further, a decrease in stomatal conductance $(42-63 \%)$ at this stage resulted in a significant increase in WUE (Tables 1, 2). In Malus spp., Sun et al. (2013) also reported a negative correlation between WUE and $g_{s}$. During fruit ripening (95 DAP in 2011), the combination of the cumulative water deficit and high VPD (Fig. 1), resulted in a further decrease in $g_{\mathrm{s}}$, causing a significant reduction in $P_{\mathrm{N}}$, which can be attributed to a reduced $C_{\mathrm{i}}$. Janoudi et al. (1993) also reported that $\mathrm{CO}_{2}$ limitation reduced $P_{\mathrm{N}}$ in cucumber plants.

Under $50 \% \mathrm{ETc}, g_{\mathrm{s}}$, and $P_{\mathrm{N}}$ decreased in cv. Mission and Super Nectar while these were maintained in cv. Da Vinci (Fig. 3). The later cultivar was also more stable for all gas-exchange traits over the sampling dates as compared to cv. Mission and Super Nectar (Figs. 2, 4). Thus, lower $g_{\mathrm{s}}$ (Fig. 3, Table 1) and the ability to sustain $P_{\mathrm{N}}$ under $50 \%$ ETc in cv. Da Vinci indicates the potential of this cultivar for physiological adaptation to water deficit conditions. These results together with the positive association of $P_{\mathrm{N}}$

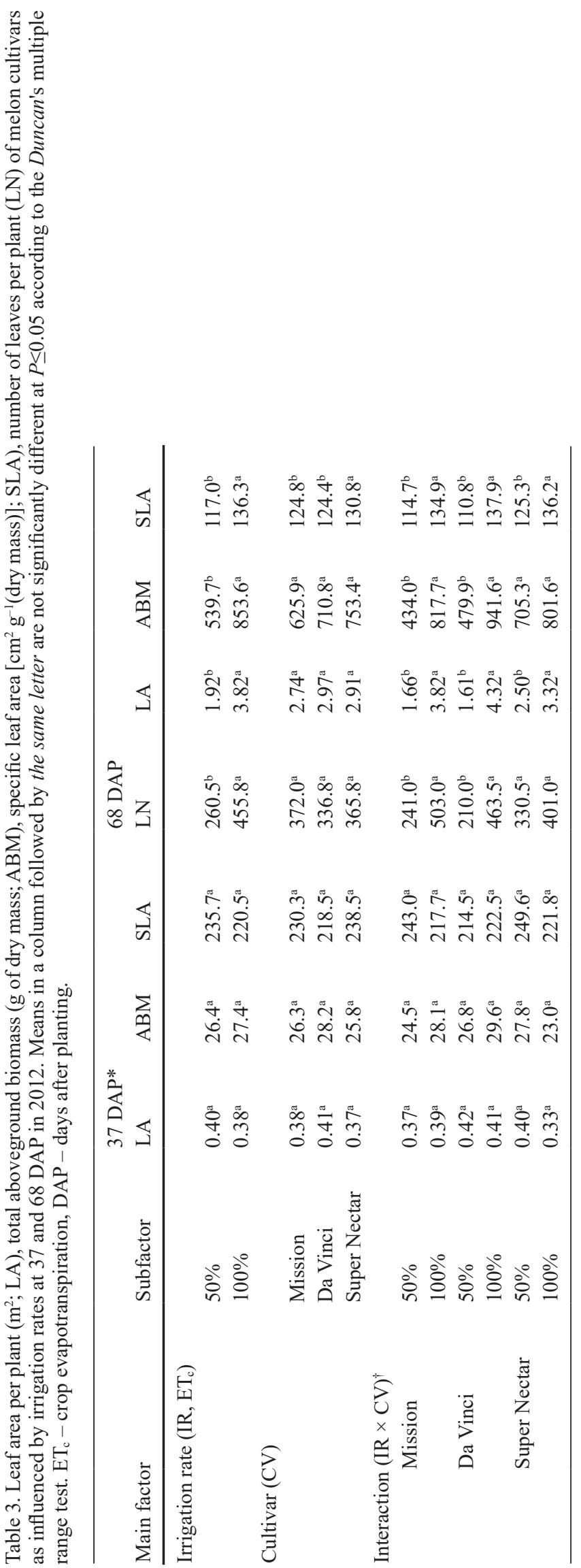




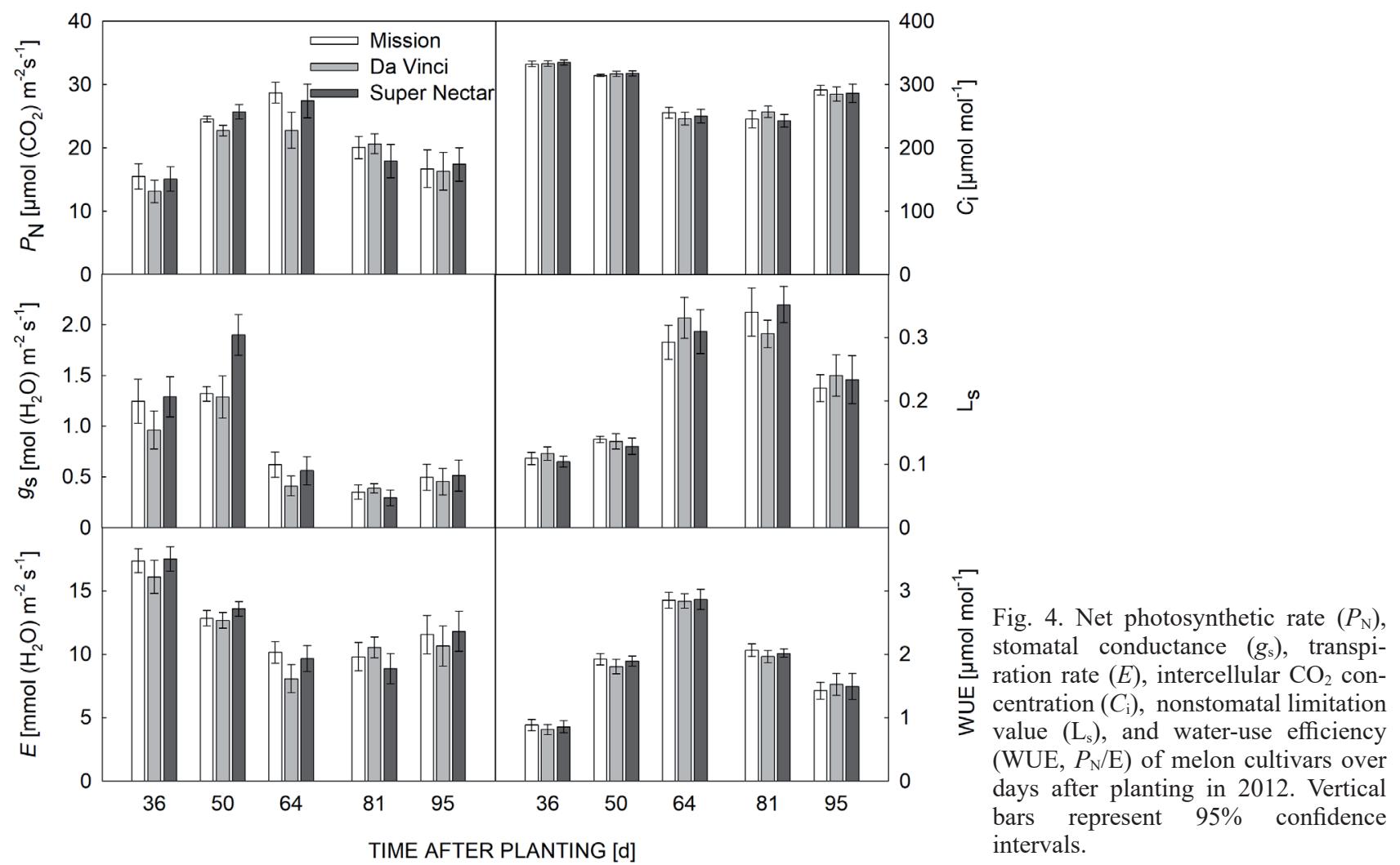

with a total fruit yield, though not statistically significant, (Table 1S) also indicates the possibility of using the leaf photosynthetic capacity as a selection criteria for drought tolerance in melons (Ashraf and Harris 2013). Conversely, the cultivar Super Nectar had a higher $g_{\mathrm{s}}$ during initial growth stages (53 DAP in 2011 and 50 DAP in 2012) (Figs. 2, 3, 4), indicating the possibility for honeydew melons to have higher transpiration requirements as compared to Tuscan and muskmelon types.

The insignificant differences between irrigation treatments for the maximum photochemical efficiency of PSII $\left(\mathrm{F}_{\mathrm{v}} / \mathrm{F}_{\mathrm{m}}\right)$ revealed that the photochemical apparatus was not damaged by the intensity of the water deficit imposed through the application of $50 \% \mathrm{ETc}$, indicating that PSII in melon was stable under water-deficit conditions. In cotton, de Brito et al. (2011) also reported no differences for quantum yield between stressed and watered conditions, despite genotypic differences for other physiological parameters, for example membrane leakage and carbon isotope composition. These results suggested that quantum yield $\left(\mathrm{F}_{\mathrm{v}} / \mathrm{F}_{\mathrm{m}}\right)$ may not be a useful trait in differentiating melon cultivars for their responses to water deficit.

No significant interactions between irrigation rate and cultivars were observed for RWC and leaf water potential $\left(\Psi_{1}\right)$ (data not shown). However, deficit irrigation caused a numerical decrease $(<0.3 \mathrm{MPa})$ in $\Psi_{1}$ in cv. Mission, and Super Nectar, while it was maintained in cv. Da Vinci. According to Hsiao (1973), water stress can be termed as mild, moderate, and severe if $\Psi_{1}$ is lowered by less than $0.8,1.2-1.5$, and $>1.5 \mathrm{MPa}$, respectively, under waterdeficit conditions. Thus, these results indicated cv. Mission and Super Nectar experienced a mild level of water stress.
The maintenance of $\Psi_{1}$ in Da Vinci can be attributed to lower $g_{\mathrm{s}}$ and $E$ in this cultivar, while a less reduction in $\Psi_{1}$ in $\mathrm{cv}$. Mission can be attributed to the enhanced root length intensity $\left(\mathrm{mm} \mathrm{cm}^{-2}\right)$ under deficit irrigation (Sharma et al. 2014), which might have increased water uptake potential in this cultivar (Table 2, Fig. 3).

Leaf area expansion is more sensitive to water stress than photosynthesis and transpiration (Subbarao et al. 1995). Under slow and gradual water deficit development, plants adjust their transpiring surface by reducing leaf growth to balance the transpiration demand with reduced water uptake (Hsiao 1982). Crop transpiration is reduced linearly with a reduction in leaf area under soil water deficit conditions (Ritchie 1985). Therefore, adjustment and maintenance of optimum leaf area under water deficit conditions is the major plant process in determining crop productivity (Subbarao et al. 1995). In our study, although the photosynthetic traits were not affected by deficit irrigation in 2012, a significant reduction in total leaf area $(50 \%)$, leaf number (43\%), and SLA (14\%) was recorded under deficit irrigation as compared to $100 \%$ ETc (Table 3). Under water deficit, reduction in leaf number and leaf area have also been reported in strawberry (Razavi et al. 2008), and SLA in Amaranthus spp. (Liu and Stützel 2004).

The ability of melons to adjust leaf area in response to deficit irrigation appears to be cultivar dependent as cv. Mission, Da Vinci, and Super Nectar decreased LA by 50, 50 , and $20 \%$ and $\mathrm{LN}$ by 60,60 , and $20 \%$, respectively. Genotypic differences for leaf area expansion under water stress have also been reported in Amaranthus spp. (Liu and Stützel 2004) and groundnut (Muchow 1985, Subbarao et 
al. 1995). However, SLA reduction under 50\% ETc was $10 \%$ more in Da Vinci than in Mission and Super Nectar, indicating a decreased transpiring area and an increased leaf thickness in Da Vinci. Further, Liu and Stützel (2004) also reported that Amaranthus genotypes differed in their water conserving strategies, cv. WS80-192 exhibited reduction in SLA to control water loss. They also argued that drought tolerance is determined by a conservative balance between the water transpiring and absorbing plant organs. Thus, plants try to control water loss by decreasing leaf area. Further, the thicker leaves have higher Chl density and exhibit more photosynthetic capacity than thinner leaves. Thus, under water deficit, the maintenance of higher $P_{\mathrm{N}}$ in Da Vinci could be attributed to greater reduction in SLA in comparison to Mission and Super Nectar.

Despite the benefit of water deficit tolerance for survival, it can have an adverse impact on yield potential. Yield responses to deficit irrigation varied among cultivars. In both years, cv. Super Nectar recorded the highest yield reductions in response to deficit irrigation, while Mission and Da Vinci had significant reductions in 2012 which can be attributed to the significant drought experienced during the fruit setting stage in 2012. The drought induced water deficit caused a reduction in leaf area and there by total crop photosynthesis decreasing crop productivity. Richards (2000) reviewed that the maintenance of total crop photosynthesis is more important than the increase in the rate of photosynthesis per unit leaf area. Reduction in leaf area and fruit yield has also been reported in strawberry under field conditions during severe deficit irrigation (Liu et al. 2007).

Generally, honeydew melon (cv. Super Nectar) takes longer time from planting to fruit ripening as compared to cantaloupe (cv. Mission) and Tuscan type melons (cv. Da Vinci). Deficit irrigation caused the lowest aboveground biomass $(\mathrm{ABM})$ reduction in cv. Super Nectar (10\%) than that in cv. Mission (50\%) and Da Vinci (50\%) (Table 3). Conversely, the highest reduction in total yield was recorded in Super Nectar (Fig. 4S). These contradictory results can be attributed to late maturity and longer cropping season of cv. Super Nectar, which was exposed to drought for longer period before the final harvest. This was also evident from the significant reduction in root length density in this cultivar at final harvest stage (Sharma et al. 2014), which might have resulted in an imbalance between water losing and absorbing surfaces. Similarly, Cattivelli et al. (2008) reviewed that earliness is an effective breeding strategy for improving yield in environments where the crops are exposed to terminal droughts.

Conclusion: The total fruit yield and biomass production of the three melon cultivars investigated in the present study were positively correlated with leaf gas-exchange parameters, leaf area, leaf number, and specific leaf area under water deficit conditions. Thus it appears that adaptation responses to water-deficit conditions in melons are related to the maintenance of gas-exchange capacity along with adequate leaf area and thus, to the total crop photosynthesis. The early maturing cultivars Mission and Da Vinci escaped the cumulative stress developed through gradual water deficit over the growing season and also exhibited water loss limiting adaptations such as a decrease in leaf area and leaf gas exchange adaptations, respectively; however, cv. Super Nectar due to late maturity and longer duration had higher yield penalties. Thus, early maturing and short duration melon cultivars that have the capacity to maintain leaf area development under water deficit conditions, can better sustain productivity in drought prone semiarid growing regions.

\section{References}

Abdulraham A.A., Oyedotun R.A., Oladele F.A.: Diagnostic significance of leaf epidermal features in the family cucurbitaceae. - Insight Bot. 1: 22-27, 2011.

Agehara S., Leskovar D.I.: Characterizing concentration effects of exogenous abscisic acid on gas exchange, water relations, and growth of muskmelon seedlings during water stress and rehydration. - J. Am. Soc. Hortic. Sci. 137: 400-410, 2012.

Allen R.G., Pereira L.S., Raes D. et al.: Crop Evapotranspiration Guidelines for Computing Crop Water Requirements. Irrigation and Drainage, Paper 56. Pp. 103-134. FAO, Rome 1998.

Ashraf M., Arfan M., Shahbaz M. et al.: Gas exchange characteristics and water relations in some elite okra cultivars under water deficit. - Photosynthetica 40: 615-620, 2002.

Ashraf M., Harris P.J.C.: Photosynthesis under stressful environments: An overview. - Photosynthetica 51: 163-190, 2013.

Blum A.: Drought resistance, water-use efficiency, and yield potential - Are they compatible, dissonant, or mutually exclusive? - Aust. J. Agric. Res. 56: 1159, 2005.

Blum A.: Plant water relations, plant stress and plant production. - In: Blum A. (ed.): Plant Breeding for Water-Limited Environments. Pp. 11-52. Springer-Verlag, New York 2011.

Boogaard R.V.D., Veneklaas E.J., Lambers H.: The association of biomass allocation with growth and water use efficiency of two (Triticum aestivum L.) cultivars. - Funct. Plant Biol. 23: 751-761, 1996.

Cabello M.J., Castellanos M.T., Romojaro F. et al.: Yield and quality of melon grown under different irrigation and nitrogen rates. - Agric. Water Manage. 96: 866-874, 2009.

Cattivelli L., Rizza F., Badeck F.W. et al.: Drought tolerance improvement in crop plants: An integrated view from breeding to genomics. - Field Crops Res. 105: 1-14, 2008.

de Brito G.G.d., Sofiatti V., de Andrade Lima M.M. et al.: Physiological traits for drought phenotyping in cotton. - Acta Sci. Agron. 33: 117-125, 2011.

De N., Ram D., Pandey S.: Physiological traits as determinant of yield in muskmelon under field conditions. - Ind. J. Horticult. 65: 40-43, 2008.

Fabeiro C., Martín de Santa Olalla F., de Juan J.A.: Production of muskmelon (Cucumis melo L.) under controlled deficit irrigation in a semi-arid climate. - Agric. Water Manage. 54: 93-105, 2002.

Fereres E., Soriano M.A.: Deficit irrigation for reducing agricultural water use. - J. Exp. Bot. 58: 147-159, 2007.

Fullana-Pericàs M., Conesa M.À., Soler S. et al.: Variations of leaf morphology, photosynthetic traits and water-use efficiency in Western-Mediterranean tomato landraces. - Photosynthetica 55: 121-133, 2017.

Goreta S., Leskovar D.I., Jifon J.L.: Gas exchange, water status, and growth of pepper seedlings exposed to transient water deficit stress are differentially altered by antitranspirants. - J. Am. Soc. Hortic. Sci. 132: 603-610, 2007.

Hamidou F., Zombre G., Braconnier S.: Physiological and 
biochemical responses of cowpea genotypes to water stress under glasshouse and field conditions. - J. Agron. Crop Sci. 193: 229-237, 2007.

Hsiao T.C.: Plant responses to water stress. - Annu. Rev. Plant Physio. 24: 519-570, 1973.

Hsiao T.C.: The soil plant atmosphere continuum in relation to drought and crop production. - In: IRRI (ed.): Drought Resistance in Crops with Emphasis on Rice. Pp. 39-52. IRRI, Los Baños 1982.

Huang Z., Zou Z., He C. et al.: Physiological and photosynthetic responses of melon (Cucumis melo L.) seedlings to three Glomus species under water deficit. - Plant Soil 339: 391$399,2010$.

Huck M.G., Ishihara K., Peterson C.M. et al.: Soybean adaptation to water stress at selected stages of growth. - Plant Physiol. 73: 422-427, 1983.

Janoudi A.K., Widders I.E., Flore J.A.: Water deficits and environmental factors affect photosynthesis in leaves of cucumber (Cucumis sativus L.). - J. Am. Soc. Hortic. Sci. 118: 366-370, 1993.

Jones H.G.: Partitioning stomatal and non-stomatal limitations to photosynthesis. - Plant Cell Environ. 8: 95-104, 1985.

Karimi S., Yadollahi A., Arzani K. et al.: Gas-exchange response of almond genotypes to water stress. - Photosynthetica 53: 29-34, 2015.

Kitroongruang N., Jodo S., Hisai J. et al.: Photosynthetic characteristics of melons (Cucumis melo L.) grown under high temperatures. - J. Jpn. Soc. Hortic. Sci. 61: 107-114, 1992.

Ko J., Piccinni G., Marek T. et al.: Determination of growthstage-specific crop coefficients (Kc) of cotton and wheat. Agric. Water Manage. 96: 1691-1697, 2009.

Kusvuran S., Dasgan H.Y., Kuçukkomurcu S., Abak K.: Relationship between drought tolerance and stomata density in melon. - Acta Hort. 871: 291-300, 2010.

Leskovar D.I., Piccinni G.: Yield and leaf quality of processing spinach under deficit irrigation. - HortScience 40: 1868-1870, 2005.

Leskovar D.I., Ward J.C., Sprague R.W. et al.: Yield, quality, and water use efficiency of muskmelon are affected by irrigation and transplanting versus direct seeding. - HortScience 36: 286-291, 2001.

Lester G.E., Oebker N.F., Coons J.: Preharvest furrow and drip irrigation schedule effects on postharvest muskmelon quality. - Postharvest Biol. Technol. 4: 57-63, 1994.

Liu F., Savić S., Jensen C.R. et al.: Water relations and yield of lysimeter-grown strawberries under limited irrigation. - Sci. Hortic.-Amsterdam 111: 128-132, 2007.

Liu F., Stützel H.: Biomass partitioning, specific leaf area, and water use efficiency of vegetable amaranth (Amaranthus spp.) in response to drought stress. - Sci. Hortic.-Amsterdam 102: 15-27, 2004.

Long R.L., Walsh K.B., Midmore D.J. et al.: Irrigation scheduling to increase muskmelon fruit biomass and soluble solids concentration. - HortScience 41: 367-369, 2006.

Mafakheri A., Siosemardeh A., Bahramnejad B. et al.: Effect of drought stress on yield, proline and chlorophyll contents in three chickpea cultivars. - Aust. J. Crop Sci. 4: 580-585, 2010.

McIntosh M.S.: Analysis of combined experiemnts. - Agron. J. 75: 153-155, 1983.

Medrano H., Parry M.A.J., Socias X. et al.: Long term water stress inactivates Rubisco in subterranean clover. - Ann. Appl. Biol. 131: 491-501, 1997.

Muchow R.C.: Canopy development in grain legumes grown under different soil water regimes in a semi-arid tropical environment. - Field Crop. Res. 11: 99-109, 1985.

Oyetunji O.J., Ekanayake I.J., Osonubi O.: Chlorophyll fluorescence analysis for assessing water deficit and arbuscular mycorrhizal fungi (AMF) inoculation in Cassava (Manihot esculenta Crantz.). - Adv. Biol. Res. 1: 108-117, 2007.

Raschke K., Hedrich. R.: Simultaneous and independent effects of abscisic acid on stomata and the photosynthetic apparatus in whole leaves. - Planta 163: 105-118, 1985.

Razavi F., Pollet B., Steppe K. et al.: Chlorophyll fluorescence as a tool for evaluation of drought stress in strawberry. Photosynthetica 46: 631-633, 2008.

Richards R.A.: Selectable traits to increase crop photosynthesis and yield of grain crops. - J. Exp. Bot. 51: 447-458, 2000.

Ritchie J.T.: A user-orientated model of the soil water balance in wheat. - In: Day W., Atkin R.K. (ed.): Wheat Growth and Modelling, Vol. 86. NATO ASI Science. Pp. 293-305, Springer-Verlag, Berlin 1985.

Romero-Munar A., Baraza E., Cifre J. et al.: Leaf plasticity and stomatal regulation determines the ability of Arundo donax plantlets to cope with water stress. - Photosynthetica 56: 698706, 2018 .

Sharma S.P., Leskovar D.I., Crosby K.M. et al.: Root growth, yield, and fruit quality responses of reticulatus and inodorus melons (Cucumis melo L.) to deficit subsurface drip irrigation. - Agric. Water Manage. 136: 75-85, 2014.

Sharma S.P., Leskovar D.I., Crosby K.M. et al.: Root growth dynamics and fruit yield of melon (Cucumis melo L.) genotypes at two locations with sandy loam and clay soils. Soil Till. Res. 168: 50-62, 2017.

Sharma, S.P., Leskovar, D.I., Volder, A. et al.: Root distribution patterns of reticulatus and inodorus melon (Cucumis melo L.) under subsurface deficit irrigation. - Irrigation Sci.: doi: 10.1007/s00271-018-0587-7, 2018.

Sharp R.E., Davies W.J.: Solute regulation and growth by roots and shoots of water-stressed maize plants. - Planta 147: 4349, 1979.

Shinohara T., Agehara S., Yoo K.S. et al.: Irrigation and nitrogen management of artichoke: Yield, head quality, and phenolic content. - HortScience 46: 377-386, 2011.

Subbarao G.V., Johansen C., Slinkard A.E. et al.: Strategies for improving drought resistance in grain legumes. - Crit. Rev. Plant Sci. 14: 469-523, 1995.

Sun X.P., Yan H.L., Kang X.Y. et al.: Growth, gas exchange, and water-use efficiency response of two young apple cultivars to drought stress in two scion-one rootstock grafting system. Photosynthetica 51: 404-410, 2013.

(C) The authors. This is an open access article distributed under the terms of the Creative Commons BY-NC-ND Licence. 